\title{
Preparation of 3D Nanoflower-like ZnO/graphene Oxide decorated with Au@AuPt Bimetallic Nanoparticles for Electrochemical Determination of Doxorubicin Hydrochloride
}

\author{
Ling Shi ${ }^{1}$, Zefeng Wang ${ }^{1,2, *}$, Lae Bai ${ }^{1}$, Guangming Yang ${ }^{1, *}$ \\ ${ }^{1}$ Engineering Research Center for Processing and Quality Control of Local Characteristic Food and \\ Consumer Goods of High Education in Yunnan Province, College of Science, Honghe University, \\ Mengzi 661199, PR China \\ ${ }^{2}$ Innovation Research Institute of Traditional Chinese Medicine (IRI), Shanghai University of \\ Traditional Chinese Medicine, Shanghai 201203, China \\ *E-mail: wangzefeng841006@163.com, yangguangmingbs@126.com
}

Received: 14 October 2021 / Accepted: 23 November 2021 / Published: 6 December 2021

\begin{abstract}
A novel 3D nanoflower-like $\mathrm{ZnO}$-graphene oxidation (3D $\mathrm{ZnO}-\mathrm{GO}$ ) nanocomposites were proposed for the first time by simple aqueous hydrothermal method and sonochemical approach. Then the Au@AuPt NPs were decorated onto 3D ZnO-GO nanocomposites to obtain a novel Au@AuPt/3D ZnO-GO nanohybrids. The obtained nanohybrids were characterized by scanning electron microscopy, transmission electron microscopy, and X-ray diffraction. The Au@AuPt/3D ZnO-GO nanohybrids were used to fabricate electrochemical sensor for detection of doxorubicin hydrochloride. The proposed sensor showed excellent electrocatalytic activity toward electrochemical oxidation doxorubicin hydrochloride. The electrochemical ocidation reaction of doxorubicin hydrochloride on modified electrode surface was a surface-controlled process, and the charge transfer coefficient $(\alpha)$ and electron transfer number (n) were 0.81 and 2 , respectively. The sensor had a wide linear range from $0.65 \mu \mathrm{M}$ to $369.45 \mu \mathrm{M}$, with the limit of detection was $0.013 \mu \mathrm{M}$. Furthermore, the proposed electrochemical sensor can be applied successfully to selective determination of doxorubicin hydrochloride in urine sample.
\end{abstract}

Keywords: Graphene oxidation; Au nanoparticles; Pt nanoparticles; Zinc oxide; doxorubicin hydrochloride; electrochemical sensor

\section{FULL TEXT}

(C) 2022 The Authors. Published by ESG (www.electrochemsci.org). This article is an open access article distributed under the terms and conditions of the Creative Commons Attribution license (http://creativecommons.org/licenses/by/4.0/). 